\title{
O SISTEMA SHAPE CODING COMO FERRAMENTA PARA A REFLEXÃO LINGUÍSTICA EM LÍNGUA PORTUGUESA PARA SURDOS*
}

\author{
Joseane Maciel Viana \\ Tatiana Bolívar Lebedeff
}

\section{Introdução}

O ensino de Língua Portuguesa - LP como segunda língua - L2 para surdos já é uma realidade legal (BRASIL, 2005; 2015), porém, há muitas dificuldades enfrentadas pelos docentes ao criar estratégias de ensino desta língua para seus alunos.

Uma dessas barreiras está na diferença de modalidades entre as duas línguas. Para o Relatório sobre a Política Linguística da Educação Bilíngue Língua Brasileira de Sinais e Língua Portuguesa (MEC/SECADI, 2014), a Língua de Sinais é a L1 dos estudantes surdos, enquanto que:

[...] a Língua Portuguesa assume o papel de segunda língua (L2) em uma segunda modalidade (M2) para os surdos, ou seja, além de ensinar uma segunda língua utilizando metodologia específica para o seu ensino, o ensino de línguas com modalidades diferentes (visual-espacial e oralauditiva) exige desenvolver metodologia para o ensino na segunda modalidade. Na educação, portanto a Língua Portuguesa será ensinada nesta qualidade (MEC/SECADI, 2014; p. 11).

A dificuldade, infere-se, pode estar em como relacionar informações morfológicas e sintáticas que são representadas linearmente na escrita da língua portuguesa para uma lógica visuoespacial com características de simultaneidade.

Lessa-de-Oliveira (2012) explica que nas línguas de sinais a imagem acústica é substituída por uma imagem visual. A autora destaca que, por sua natureza auditiva o significante acústico se articula de forma linear, já o significante das línguas visuoespaciais incorpora a natureza tridimensional do

*DOI - 10.29388/978-65-86678-60-4-0-f.205-218 
espaço visual em que se articula. Ou seja, os elementos constitutivos do sinal (configuração de mão, ponto de articulação, movimento, orientação da palma da mão e expressões não manuais) ocupam o espaço tridimensional, de forma simultânea. A presença de cada um desses elementos é percebida no espaço, ao mesmo tempo, enquanto o sinal está sendo enunciado.

Levando em consideração que a língua é visual e tridimensional, é importante discutir sobre a experiência visual dos surdos no processo de escolarização e no ensino de língua, seja ela L1 ou L2/ língua de leitura. Lebedeff (2017) comenta que este conceito engloba as possibilidades de interação e compreensão do mundo, pelos surdos, através da visão. A autora salienta que não é uma situação biológica de compensação, mas sim, uma organização linguística, cognitiva e cultural das pessoas surdas. Quadros, (2003; p. 93) explica que as experiências visuais são as que perpassam a visão. Para a autora a experiência é visual desde o ponto de vista físico (os encontros, as festas, as estórias, as casas, os equipamentos, entre outros) até o ponto de vista mental (a língua, os sonhos, os pensamentos, as ideias, entre outros).

Nesse sentido, de acordo com Lebedeff (2017) artefatos culturais que privilegiam a visão, tais como a língua de sinais, o Letramento Visual, as modificações arquitetônicas, as inovações tecnológicas, entre outros, são desenvolvidos, portanto, pela e para a comunidade surda, para dar conta da interação no mundo e compreensão deste próprio mundo que prescinde de som. A autora propõe, ainda, a necessidade do tensionamento de uma "visualidade aplicada", ou seja, que as práticas pedagógicas, os artefatos tecnológicos, as arquiteturas curriculares, entre outros, sejam problematizados e propostos a partir da compreensão da experiência visual.

$\mathrm{Na}$ mesma linha de discussão, levando em consideração as experiências visuais das pessoas surdas, Lacerda, Santos e Caetano (2011) destacam a necessidade de proposição de uma pedagogia que atenda às necessidades dos alunos surdos que se encontram imersos no mundo visual e apreendem, a partir das experiências visuais, a maior parte das informações para a construção do seu conhecimento. As autoras salientam que não basta apenas apresentar os conteúdos em Libras, é necessário explicar os conteúdos, em sala de aula, utilizando o potencial visual intrínseco a Libras. As autoras defendem, para os surdos, a Pedagogia Visual, sabendo-se que:

Para os surdos os conceitos são organizados em língua de sinais, que por ser uma língua viso-gestual, pode ser comparada a um filme, já que o 
enunciador enuncia por meio de imagens, compondo cenas explorando a simultaneidade e a consecutividade de eventos (LACERDA; SANTOS; CAETANO, 2011, p. 104).

É importante salientar que o documento intitulado "Relatório sobre a Política Linguística de Educação Bilíngue - Língua Brasileira de Sinais e Língua Portuguesa" (MEC/SECADI, 2014), elaborado pelo Grupo de Trabalho, designado pelas Portarias no $1.060 / 2013$ e no 91/2013 do MEC/SECADI que discutiu e publicou um relatório defendendo a educação bilíngue para surdos no Brasil apresenta a importância da experiência visual não apenas para a aprendizagem, mas também, para o desenvolvimento da identidade surda:

Para a pessoa surda, a relevância dos aspectos visuais traz como consequência a invenção de artefatos culturais que usam a visão, como seja: a língua de sinais, a imagem, o letramento visual ou leitura visual. Esses artefatos são importantes para criar o ambiente necessário ao desenvolvimento da identidade surda e requerem o uso de mecanismos adequados para sua presença acontecer, tendo em vista que se diferencia constituindo significantes, significados, valores, estilos, atitudes e práticas (p. 14).

Entretanto, Peluso e Lodi (2015) salientam que não se pode banalizar a visualidade dos surdos, pois não é algo que se pode ensinar. A visualidade, de acordo com os autores, é uma maneira de estar no mundo, que está fundamentalmente determinada pela língua e pelo discurso. Os autores sugerem que a concepção de que os surdos organizam o mundo de modo linguístico e enunciativo no plano visual possibilita considerar, também, que a visualidade não lhes é externa, mas sim, constitutiva de sua subjetividade e da forma que organizam sua realidade.

Nesse sentido, como comenta Santos (2020; p.80) "o surdo não é visual, a Língua de Sinais é". A visualidade das línguas de sinais, segundo o autor, que se materializa na própria combinação de movimentos, pontos de articulação, configuração de mãos, delimitações espaciais e expressões faciais, possibilita a exploração de outros recursos visuais.

Com relação a experiência visual dos surdos, que traça um percurso linguístico e cultural, Santos (2020) argumenta que, ao assumir-se a perspectiva da visualidade como constitutiva da língua de sinais, e esta, por sua vez, constitutiva do sujeito usuário da Libras há a demanda da escola por 
"iniciativas que possam prover condições visuais eficientes para educação de surdos, tanto em ambiente bilíngue quanto inclusivo" (p.15). Para o autor é necessário propor aos surdos, em seu contexto educacional, práticas e recursos didáticos que utilizem e explorem vivências visuais.

Oliveira (2009) problematiza o processo de leitura e escrita das crianças surdas brasileiras, mostrando como possibilidade de interpretação a visualização dos textos. A autora realizou uma análise da escrita de chineses, os quais utilizam ideogramas para registrar a língua oral, como um comparativo à escrita alfabética, outra forma de registro de outros idiomas, como a Língua Portuguesa brasileira. Oliveira propõe o conceito de consciência visual, buscando, assim, equacionar o problema da descontinuidade entre os dois sistemas linguísticos aos quais o aluno surdo é exposto.

A autora defende que uma metodologia própria de ensino e aprendizagem para surdos, considerando a possibilidade da estruturação de uma prática pedagógica voltada para atividades que estimulem a Consciência Visual, pode favorecer a produção da escrita. De acordo com Oliveira (2009), o surdo, ao longo da sua educação, se apropria de "imagens visuais", através das quais, a partir da representação interna em língua de sinais, ele constrói o conhecimento sobre o objeto de estudo. Comenta que, após este processo, ele estaria pronto para desenvolver a escrita, utilizando a base alfabética. Desta forma, a consciência visual se mostra como um "mecanismo de elaboração psíquica sustentada na: representação visual do objeto - a imagem; [e na] abstração do objeto como unidade constituída de partes" (OLIVEIRA, 2009, p. 190). Deste processo resulta a representação simbólica do objeto, primeiramente através da língua de sinais e posteriormente da escrita alfabética. Para mediar o desenvolvimento da linguagem escrita do surdo, discute ser imprescindível a presença de um sujeito bilíngue, com fluência em língua de sinais e na língua oral escrita, o qual poderá interferir no processo de aquisição da linguagem escrita. Somente desta forma, segundo a autora, poderá haver a expansão da consciência visual do sujeito surdo.

Esta introdução buscou provocar o leitor a formular uma pergunta: como possibilitar visualidade na aprendizagem da língua escrita considerando as diferenças de modalidade entre as línguas? O presente capítulo tenta responder, em parte, a pergunta, ao apresentar uma possibilidade de visualização da gramática da Língua Portuguesa para auxiliar a compreensão 
escrita por alunos surdos: a adaptação do sistema Shape Coding (EBBELS, 2007; 2014).

O Shape Coding foi desenvolvido para o trabalho com crianças e jovens com dificuldade no desenvolvimento da modalidade escrita da Língua Inglesa, recepção e produção. Para Ebbels et al (2014) o Shape Coding é uma forma de trabalhar a Língua Inglesa escrita através de cores e formas que refletem, de maneira explícita, aspectos da gramática da língua ao utilizar recursos visuais.

Apesar de desenvolvido para crianças ouvintes, o Shape Coding tem sido utilizado na educação de surdos em escolas inglesas como a Oak Lodge School (LEBEDEFF, 2015), na Figura 1, e Heathland ${ }^{1}$ (Figura 2), em uma escola escocesa, a Moray House School Education ${ }^{2}$, que já colocaram em suas estruturas pedagógicas disponibilizadas nos seus respectivos materiais o uso deste código visual para a reflexão sobre a Língua Inglesa escrita.

Figura 1: Uso do Shape Coding com surdos na Oak Lodge

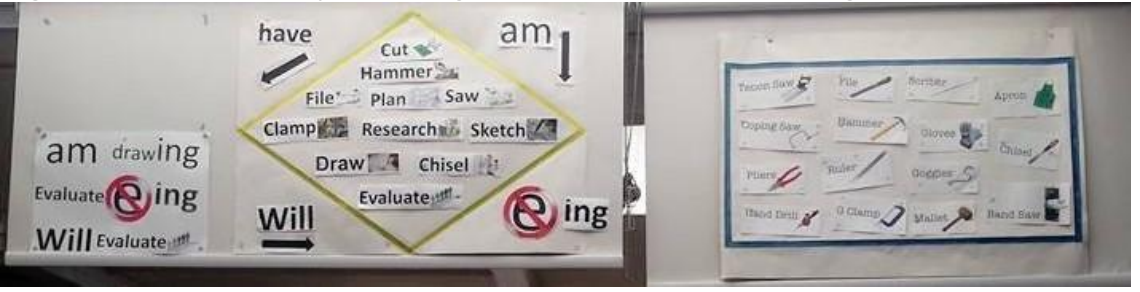

Fonte: Lebedeff (2015)

Figura 2: Formas no Shape Coding utilizado na Moray House School Education

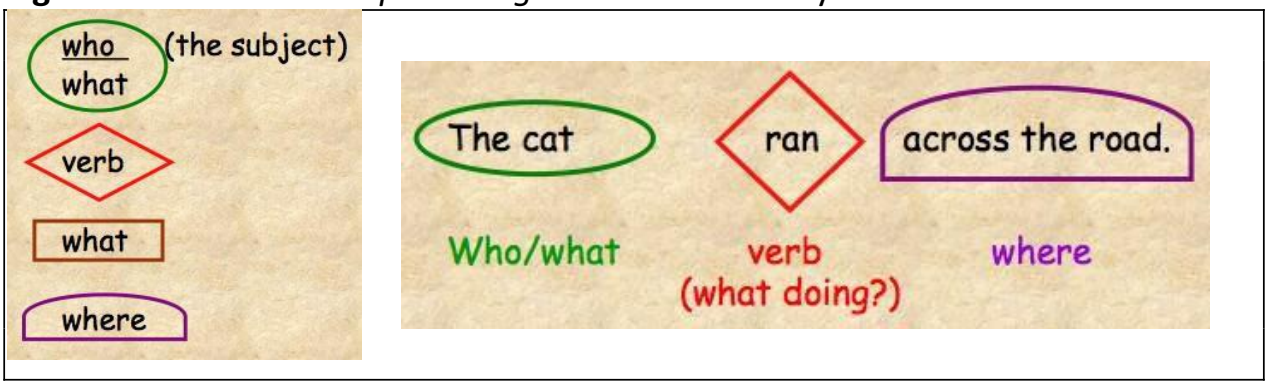

Fonte: http://www.ssc.education.ed.ac.uk/courses/deaf/djan102i.html (2019)

${ }^{1}$ Maiores informações podem ser adquiridas através do sítio:
https://heathlands.herts.sch.uk/upperschool/reading/
${ }^{2}$ Maiores informações podem ser adquiridas através do sítio eletrônico:
http://www.ssc.education.ed.ac.uk/courses/deaf/djan102i.html


No Brasil, Sampaio (2018) iniciou o trabalho com o mesmo código na educação de surdos, utilizando as marcações de tempos verbais no trabalho com o Modo Indicativo com alunos de Educação de Jovens e Adultos. Sampaio (2018) testou a inserção dos marcadores temporais nos verbos escritos em LP. No entanto, a autora não fez proposições de novos marcadores que contemplassem as lacunas no Shape Coding para a gramática da Língua Portuguesa.

Diante disto, como uma continuação do trabalho de Sampaio (2018), foi proposta a adaptação e ampliação do Shape Coding para a gramática da LP em Viana (2019), com base na visualidade surda e nas relações entre as duas línguas - LP e Libras, a fim de que se pudesse ofertar uma ferramenta de apoio para a análise e compreensão linguística da Língua Portuguesa como língua de leitura. A seguir, serão apresentados e exemplificados os resultados da tradução e adaptação do sistema.

\section{Descrição, tradução e adaptação do sistema Shape Coding, de Susan Ebbels}

A distância entre os dois casos de uso de shape coding (clínica de Susan Ebbels e escola de surdos) se desdobra em muitos aspectos: o contexto de trabalho (este escolar e aquele terapêutico), o linguístico (este bilíngue e aquele monolíngue), o modal, ou seja, o fato de que para surdos estão envolvidas duas modalidades linguísticas, entre outros fatores Salienta-se aqui, portanto, que esta adaptação envolve o trabalho com duas línguas e duas modalidades, enquanto que nos estudos de Susan Ebbels é realizado uma terapia com falantes da mesma língua que escrevem.

O desenvolvimento das atividades envolvendo o Shape Coding dá ênfase no trabalho explícito com a gramática da LP. Mesmo que isso pareça estranho ao se pensar em ensino de segunda língua, Sampaio (2018), almejando que seus alunos soubessem utilizar os verbos nos devidos tempos, utilizou-se das estratégias visuais do Shape Coding e percebeu que "pela ênfase na mudança dos sufixos dos verbos, os alunos puderam entender o motivo das mudanças nesses e assim iniciar um processo de decodificação dos verbos nos textos" (p. 87). 
Sampaio (2018) desenvolveu uma linha do tempo (Figura 3) para ilustrar as marcações de acordo com o sistema de Ebbels $(2007,2014)$. Nesta linha, apenas estão marcados os grandes tempos, passado, presente e futuro, sem fazer menção aos diversos tempos de que existem dentro de cada um destes. Além disto, a pesquisadora trabalhou com o Modo Indicativo, e mostrou em suas pesquisas que o resultado foi satisfatório ao ponto de aparecer os diferentes tempos na produção textual dos alunos surdos.

Figura 3: Linha do tempo adaptada por Sampaio partir do Shape Coding

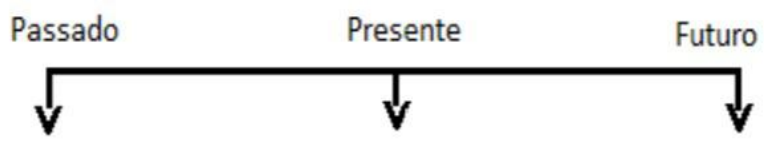

Fonte: Sampaio (2018; p.15)

No decorrer das atividades em sala de aula, sendo Libras a língua de instrução, a autora evidenciava a mudança dos sufixos e explicava o que seria o radical e porque estava modificando o "final" da palavra. Isto auxiliou os alunos a compreenderem textos e escreverem frases sobre diferentes momentos da vida, como pode ser observado na Figura 4.

Figura 4 - Atividade com a linha do tempo e organização dos tempos verbais

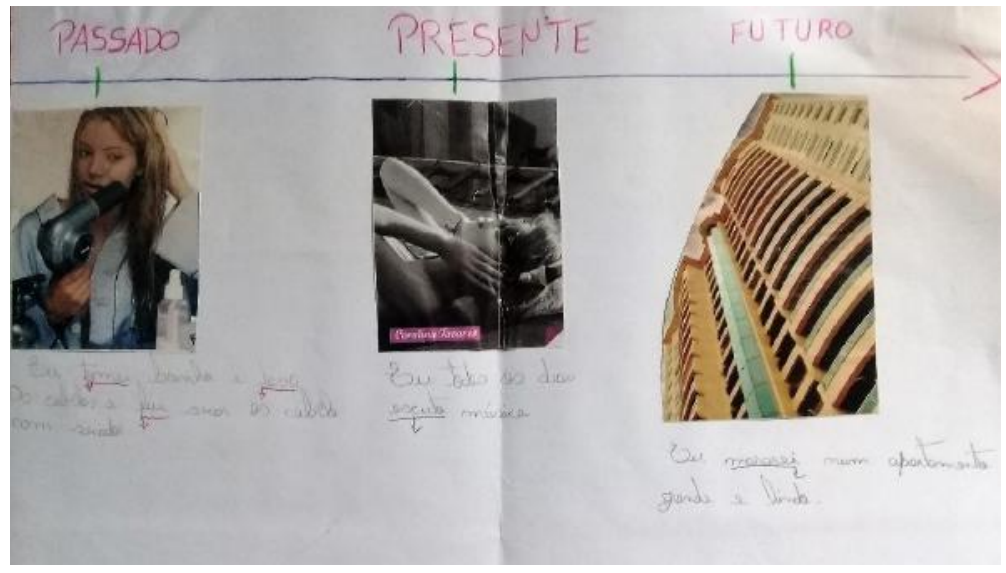

Fonte: Sampaio $(2018$, p.62) 
A partir dos resultados significativos de Sampaio (2018), iniciou-se a tradução e adaptação de outros elementos do sistema. Para a descrição do sistema criado por Susan Ebbels, foram consultados artigos da criadora do sistema em parceria com outros pesquisadores, disponíveis na internet, e um vídeo da autora no canal da SAGE Publishing ${ }^{3}$, editora internacional interessada na publicação de conteúdos inovadores de alta qualidade na área acadêmica e profissional. A primeira tentativa de explicação deste sistema visual, composto de formas e cores, foi em 2007, no artigo "Ensinando gramática para crianças em idade escolar com comprometimentos linguísticos específicos com o uso do Shape Coding" (EBBELS, 2007) ${ }^{4}$. Este texto foi a base do sistema aqui descrito, porém com retificações propostas no vídeo de 2014, trabalhadas já nos experimentos dos outros dois artigos do mesmo ano: Ebbels et al (2014) e Kulkarni, Pring e Ebbels (2014).

Para Ebbels et al (2014) Shape Coding é uma forma de trabalhar a Língua Inglesa escrita através de cores e formas que refletem, de maneira explícita, as regras da língua. A criadora deste sistema traz a ideia de recursos visuais para auxiliar na compreensão do funcionamento linguístico (p. 32). Em 2007, Ebbels propôs uma lista de cores para diferentes classes de palavras, tendo como precursor o esquema pensado por Lea $(1965,1970)$, o The Colour Pattern Scheme. Ela ainda se debruçou sobre diversos estudos que trabalhavam com formas geométricas no ensino de línguas. A fim de combinar ferramentas e criar algo mais complexo, para utilizar apenas um sistema que abarcasse estruturas frasais, análise de orações e textos, além de poder dar enfoque na flexão verbal, surgiu o Shape Coding (EBBELS, 2007, p. 69).

De acordo com Ebbels (2007), "no sistema Shape Coding, as cores são usadas para demarcar classes gramaticais a que as palavras pertencem e as formas para significar a função e posição sintáticas das mesmas em sentenças" (p. 70). Ou seja, dentro das diferentes formas utilizadas neste sistema, os alunos encontrarão as palavras ("partes das frases") as quais comumente

\footnotetext{
${ }^{3}$ Maiores informações sobre a editora SAGE Publishing disponíveis no website https://us.sagepub.com/en-us/sam

4 "Teaching grammar to school-aged children with specific language impairment using Shape Coding" (EBBELS, 2007)
} 
ocupam aquelas funções sintáticas. Isto pode representar uma maneira de estudo e fixação através de relações psico e metalinguísticas que poderão construir o conhecimento acerca do uso da linguagem escrita pelo aluno. Com estes referentes visuais, entende-se que o aprendizado da linguagem escrita se torna mais visual e acessível também aos surdos.

As cores foram ressignificadas no sistema Shape Coding entre as publicações de 2007 e 2014. A figura 5 mostra as imagens das versões inicial e final da tabela de cores do sistema, apresentadas em Ebbels (2007) e no vídeo do canal SAGE (EBBELS, 2014), respectivamente:

Figura 5: Shape Coding - cores

\begin{tabular}{|c|c|c|c|c|}
\hline \multirow[b]{2}{*}{ Colour } & \multirow[b]{2}{*}{ Part of speech } & \multirow[b]{2}{*}{ Examples } & \multicolumn{2}{|c|}{ Shape Coding - colours } \\
\hline & & & \multirow[b]{2}{*}{ Noun / Pronouns } & \multirow[b]{2}{*}{ (boy, table, I) } \\
\hline Red & Noun/pronouns & boy, table, I & & \\
\hline Pink & Det/possessive pronouns & the, a, my & Det / Possessive pronouns & (the, a, my) \\
\hline Yellow & Verb & push, melt & Verb & (push, melt) \\
\hline $\begin{array}{l}\text { Green } \\
\text { Blue }\end{array}$ & $\begin{array}{l}\text { Adjective } \\
\text { Preposition }\end{array}$ & $\begin{array}{l}\text { hard, sad } \\
\text { in, through }\end{array}$ & Adjective & (hard, sad) \\
\hline Purple & Coordinating conjunction & and, but, or & Preposition & (in, through) \\
\hline \multirow[t]{4}{*}{ Orange } & Subordinating conjunction & because, if & Adverb & (quickly, carefully) \\
\hline & & Ebbels (2007) & Coordinating conjunction & (and, but, or) \\
\hline & & & Subordinating conjunction & (because, if) \\
\hline & & & & Ebbels (2014b) \\
\hline
\end{tabular}

Fonte: Viana (2019, p. 53)

Em uma primeira análise, percebe-se a mudança de cores para representar as palavras pertencentes às classes gramaticais verbos e preposições, além da inclusão da classe dos advérbios com a cor marrom. As cores foram ressignificadas no sistema Shape Coding para atender as demandas que se apresentaram entre os anos de 2007 e 2014. Em uma síntese, de acordo com a tradução de Viana (2019), tem-se: 
Tabela 1: Cores no sistema Shape Coding

\begin{tabular}{|c|c|}
\hline \multicolumn{2}{|c|}{ SHAPE CODING - CORES } \\
\hline CORES & SIGNIFICADO \\
\hline VERMELHO & SUBSTANTIVOS E PRONOMES PESSOAIS \\
\hline ROSA & PRONOMES POSSESSIVOS \\
\hline AZUL & VERBOS \\
\hline VERDE & ADJETIVOS \\
\hline AMMARELO & PREPOSIÇÕES \\
\hline MARROM & ADVÉRBIOS \\
\hline ROXO & CONJUNÇÕES COORDENATIVAS \\
\hline LARANJA & CONJUNÇÕES SUBORDINATIVAS \\
\hline
\end{tabular}

Fonte: Viana (2019; p.53)

Percebe-se que as cores referentes aos verbos e pronomes são trocadas entre si após Ebbels (2007), com o argumento, apresentado em Ebbels et al (2014) de que a cor amarela para a análise do funcionamento de verbos em frases e textos não ficava saliente o suficiente.

Os alunos são chamados a sublinharem as palavras com a cor de acordo com a classe gramatical a qual ela pertence, mas o uso de todas as cores propostas não ocorre no primeiro momento, é claro. Conforme os estudos gramaticais vão se aprofundando nas terapias (modo como tem sido trabalhado o Shape Coding com crianças com comprometimentos linguísticos), novas cores vão sendo apresentadas. Na adaptação proposta por Viana (2019), foi necessária a criação de cores para as demais classes gramaticais utilizadas na Língua Portuguesa com maior frequência e regramento como, por exemplo os artigos e numerais, e ainda uma diferenciação entre as marcações dos diferentes tipos de pronomes.

As funções sintáticas, por sua vez, são representadas por formas que englobam uma ou mais palavras e, se confeccionadas para uso didático, são facilmente movimentadas de acordo com a necessidade da atividade proposta. Uma apresentação simplificada destas formas no vídeo disponibilizado por SAGE (EBBELS, 2014) é a apresentada na figura 6: 
Figura 6: Formas utilizadas no Shape Coding

\section{Shape Coding - shapes}

- Phrases grouped with shapes and linked with colour, a question and a symbol

- 'Subjects' and 'objects' have different shapes

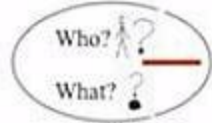

NP: Subject

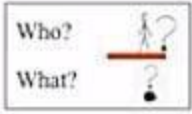

NP: Object
- Extra shapes

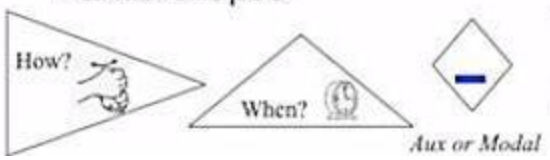

What doing?

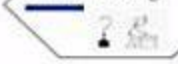

Vicrb Phrase

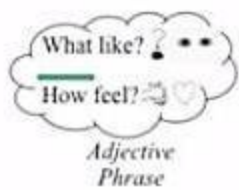

Phrase

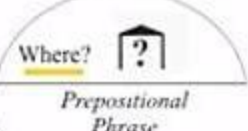

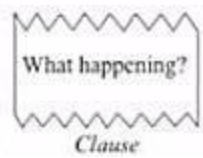

Phrase

Fonte: Ebbels (2014)

De acordo com Ebbels $(2007 ; 2014)$, as formas do sistema Shape Coding são utilizadas quando necessitamos evidenciar funções sintáticas nas sentenças. Estas funções podem ser encontradas na análise da gramática da LP, porém, devido às peculiaridades da Língua Inglesa e do Língua Portuguesa, algumas adaptações precisam ser levadas em conta. Viana (2019), quando propôs a tradução literal do sistema para análise sintática, percebeu essas diferenças e algumas lacunas nas marcações para análise da LP usada no Brasil:

Algumas descrições puderam ser facilmente identificadas e relacionadas com elementos da análise gramatical da Língua Portuguesa, porém não todas. Um exemplo é a "frase adjetiva" que, em um primeiro momento se assemelha ao nosso predicativo do sujeito, mas a regra de possuir pelo menos um adjetivo foge das exigências para esta função sintática. (VIANA, 2019, p. 55) 
A autora não inseriu novas formas para completar o sistema de Ebbels, por entender que, mesmo tendo diferentes relações entre classes gramaticais (os sublinhados coloridos) e as funções sintáticas nas duas línguas. Com o uso experimental em salas de aula do ensino fundamental, Viana percebeu, como um dos pontos positivos do sistema, a sobreposição de informações de forma visual, o que auxiliou na identificação gramatical ao mesmo tempo em que as marcações não interferiram na compreensão geral dos alunos.

O sistema Shape Coding, além de cores e formas, possui alguns marcadores para flexão verbal e concordância verbal/nominal através de sublinhados. A utilização destes marcadores destaca funções verbais as quais auxiliam os alunos em um primeiro momento de compreensão através da análise gramatical (EBBELS, 2014). Estas pistas visuais foram as mais utilizadas e apreendidas pelos alunos surdos, principalmente pela função central dos verbos em sentenças na ordem direta, mais comumente escritas pelos usuários de uma língua como língua estrangeira ou segunda língua. Utilizando como base as explicações no vídeo apresentado por Susan Ebbels (2014), foi desenvolvida a tabela 3 , abaixo, para sintetizar as ideias propostas:

Tabela 2: Verbos no sistema Shape Coding (A)

\begin{tabular}{||c|c|c|c|c|}
\hline & \multicolumn{5}{|c|}{ SHAPE CODING } \\
\hline Marcador & & & $\longleftarrow$ & \\
\hline Significado & Singular & Plural & $\begin{array}{c}\text { Particípio } \\
\text { passado }\end{array}$ & Gerúndio \\
\hline
\end{tabular}

Fonte: Viana (2019; p. 56)

Tabela 3: Verbos no sistema Shape Coding (B)

\begin{tabular}{|c|c|c|c|}
\hline & \multicolumn{3}{|c|}{ SHAPE CODING } \\
\hline Marcador & $\downarrow$ & $\sqrt{ }$ & \multirow{2}{*}{ Futuro } \\
\hline Significado & Presente & Passado & \multicolumn{2}{|c|}{} \\
\hline
\end{tabular}

Fonte: Viana (2019; p.56)

A partir das informações das Tabelas 3 e 4, Viana (2019) evidenciou as lacunas que se criaram pelas diferenças entre a Língua Inglesa e a Língua Portuguesa. Um dos complicadores do estudo da LP escrito como língua de leitura, ou L2M2 das pessoas surdas são as múltiplas possibilidades de registro 
de uma ação no tempo pretérito, por exemplo. Os Modos Verbais e os diferentes tempos dentro de cada um se mostram como um desafio para professores desta língua, neste contexto de ensino. Em Libras é possível falar sobre fatos nos diferentes tempos marcados morfologicamente na Língua Portuguesa, porém não há mudança significativa na execução dos sinais, pois esta relação é feita na construção das sentenças.

Utilizar a Língua Brasileira de Sinais é diferente de analisá-la. Logo, para o estabelecimento de relações metalinguísticas entre ela e a LP serão necessárias novas marcações, inclusive na sinalização. Viana (2019) evidencia esta necessidade ao referir-se aos grandes tempos com sinais-combinados localizados no braço, conforme imagem abaixo:

Figura 7: Momento de Enunciação e Pontos de Referência em LIBRAS
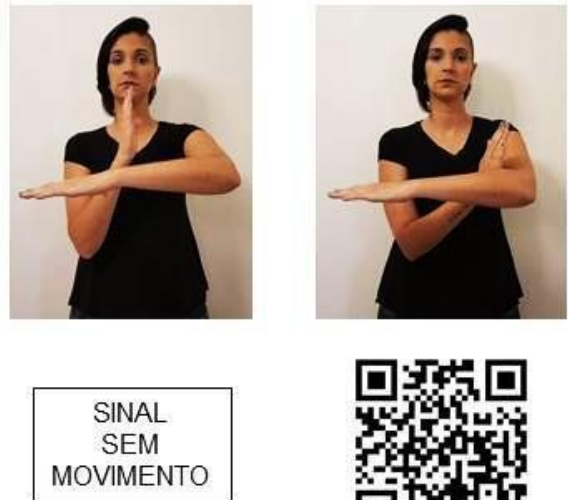

Fonte: Viana (2019, p.86)
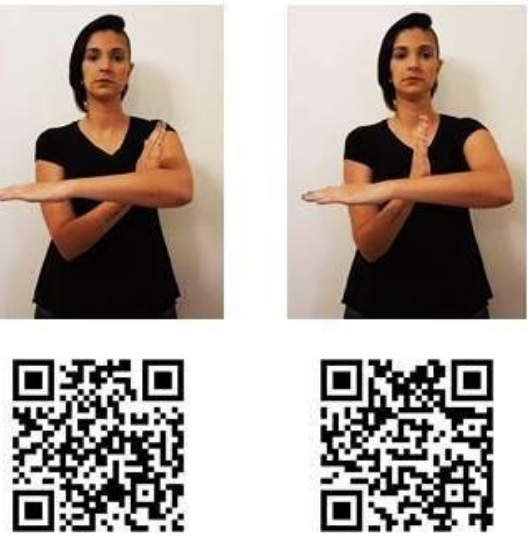
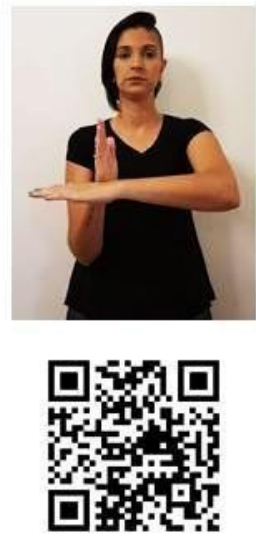

Além disso, sinais-combinados para os modos verbais, criados em conjunto com os alunos, foram registrados e discutidos pela autora com base na Libras em busca de uma construção de Consciência Visual (OLIVEIRA, 2009) para a ampliação da competência linguística dos alunos surdos. Logo, para serem utilizados com pistas visuais com os alunos surdos, a tradução do sistema Shape Coding foi adaptada, recebendo novos marcadores.

Tendo sido construídos para ser uma pista visual relacionada ao sinalcombinado em Libras, as "ponteiras" dos sublinhados dos tempos verbais nos Modos indicativo, subjuntivo e imperativo foram modificadas a fim de lembrar 
os sinais ACONTECER, IMAGINAR e JÁ, respectivamente (Viana, 2019). Na mesma proposta de adaptação para a gramática da Língua Portuguesa, a autora indica colocar a sigla específica de cada tempo verbal abaixo da ponteira, em uma análise mais aprofundada. Visualmente, em Libras e em uma adaptação do Shape Coding, as marcações ficaram assim:

Figura 8: Modos verbais em Libras e Shape Coding

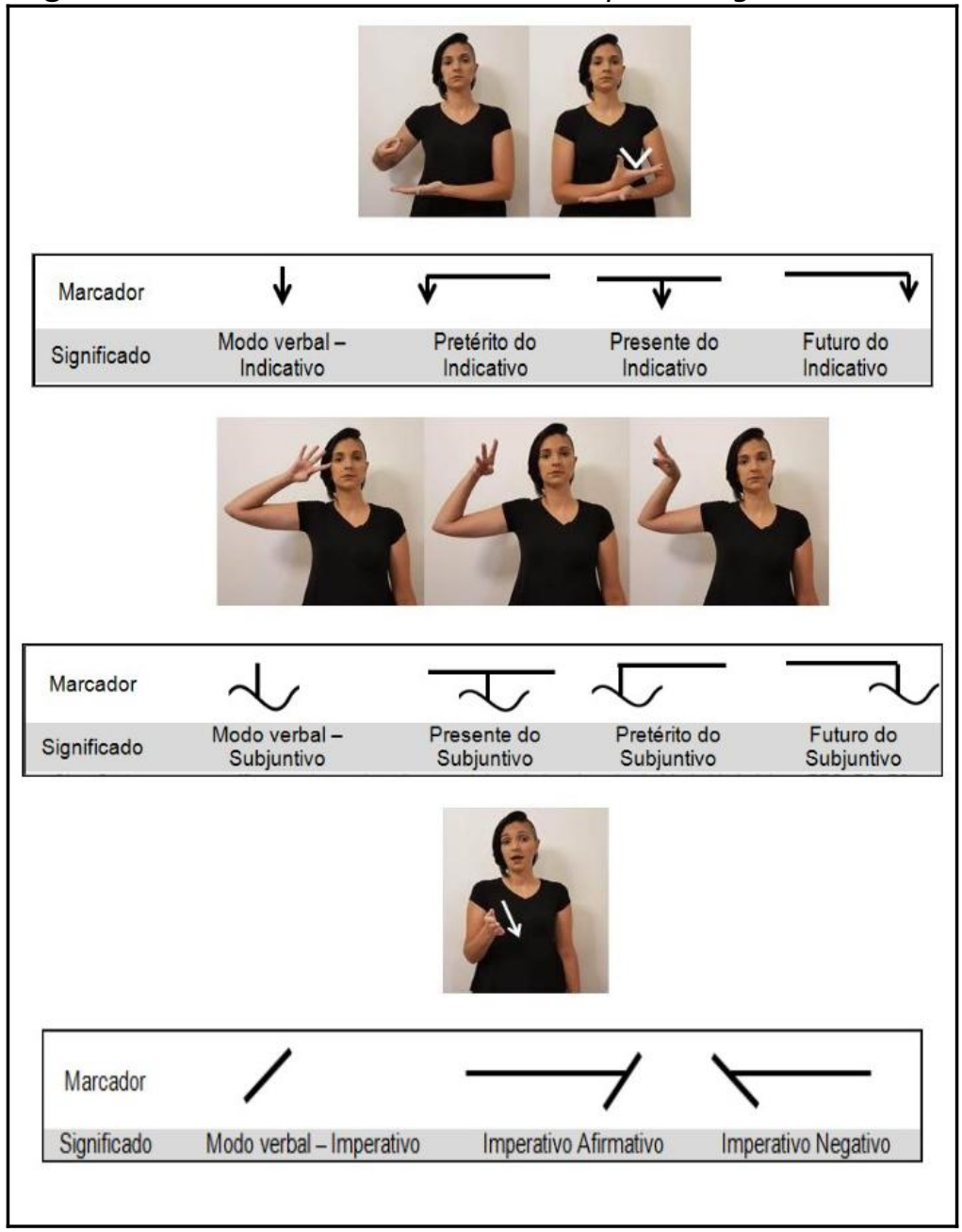

Fonte: Elaborado pelas autoras com base em Viana (2019) 
A adaptação do Shape Coding traz, segundo Viana (2019), a possibilidade de reflexão sobre a L1 e sobre a L2M2 quando se trabalha com alunos surdos, principalmente daqueles com surdez mais profunda, que não se utilizam de momentos de oralização. A estes alunos chama à atenção toda a forma de recurso visual utilizado em sala de aula.

\section{Considerações finais}

Estudos com a aplicação deste sistema, e mais precisamente da análise verbal em LP com surdos brasileiros, estão começando a acontecer e já demonstram o potencial do sistema para auxiliar na compreensão de um texto escrito. Sampaio (2018) experimentou utilizar as marcações verbais originais em sala de aula com alunos surdos, no trabalho com tempos simples do Modo Indicativo e teve êxito nas atividades propostas. A autora sugere que o Shape Coding pode ser uma possibilidade visual para os alunos surdos perceberem as diferenças na escrita de verbos na Língua Portuguesa, nessas primeiras inserções práticas do sistema.

Viana (2019), com alunos de sexto ano, utilizou as pistas visuais do Shape Coding referentes ao reconhecimento de classes gramaticais no contexto do estudo vocabular dos móveis da casa. Através de uma atividade que teve início no uso prático das palavras ao descreverem suas casas com o auxílio visual de uma maquete, eles foram orientados na leitura e escrita de textos sobre o mesmo assunto. Durante o contato com a Língua Portuguesa escrita, as cores designadas para a marcação dos artigos, substantivos e pronomes foram de grande auxílio na compreensão do uso dos mesmos e na sua relação de concordância nominal. A autora utilizou pré-teste e pós-teste após refletir, utilizando o Shape Coding em sala de aula, junto com os alunos, o uso das classes. No pós-teste teve como resultados que os alunos conseguiram utilizar adequadamente os artigos indefinidos, além dos definidos, e a substituição, com propriedade, de substantivos por pronomes pessoais do caso reto.

Já com alunos de nono ano, Viana (2019) experimentou a aplicação das novas marcações para os modos verbais, em especial o Modo Subjuntivo quando em períodos compostos com o Modo Indicativo. A atividade realizada em grupo teve como resultado produções frasais com o uso correto dos verbos, como mostra a figura 9. A autora salienta que os alunos compararam o 
que "era real" e o que "poderia ser real", percebendo o significado de construções morfológicas específicas para modos verbais em Língua Portuguesa.

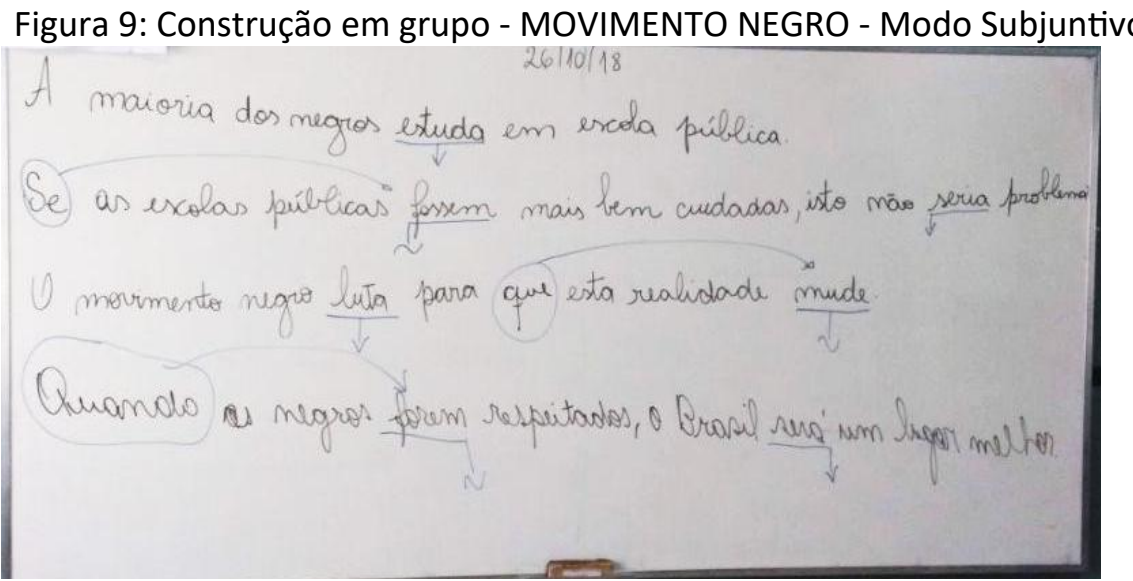

Fonte: Viana (2019, p. 87)

O objetivo geral deste capítulo foi apresentar a tradução e a adaptação do sistema Shape Coding para a sua utilização em sala de aula com estudantes surdos, na análise gramatical da Língua Portuguesa. É importante destacar que o Shape Coding não se configura como um "método" de ensino de língua escrita. É, com certeza, uma importante ferramenta para o dia-a-dia na sala de aula, que exige, dos professores, um conhecimento profundo tanto da gramática da LP como da Libras, a fim de possibilitar aos alunos a comparação e contrastação entre a L1 e a L2M2. Deste modo, a fluência na Libras é algo indispensável, tanto nos primeiros contatos com a literatura sobre o tema, assim como na prática em sala de aula.

\section{Referências}

BRASIL. Decreto no 5.626, de 22 de dezembro de 2005. Disponível em: https://www2.camara.leg.br/legin/fed/decret/2005/decreto-5626-22dezembro-2005-539842-publicacaooriginal-39399-pe.html. Acesso em: 26 out. 2019. 
BRASIL. Lei № 13.146, de 6 de julho de 2015. Disponível em: http://www.planalto.gov.br/ccivil_03/_ato2015-2018/2015/lei/l13146.htm. Acesso em: 26 out. 2019.

EBBELS S. H. Teaching grammar to school-aged children with Specific Language Impairment using Shape Coding. Child Language Teaching and Therapy Journal, n. 23, 2007, p. 67-93. Disponível em:

https://journals.sagepub.com/doi/pdf/10.1191/0265659007072143. Acesso em: 15 jan. 2018.

EBBELS S. H. et al. Improving comprehension in adolescents with severe receptive language impairments: a randomized control trial of intervention for coordinating conjunctions. International Journal of Language and

Communication Disorders, jan./fev., 2014, v. 49, n. 1, p. 30-48.

EBBELS S. H. Vídeo: Susan Ebbels talks about the SHAPE CODING system. Website YouTube. SAGE Publishing. 2014b. Disponível em: https://www.youtube.com/watch?v=Ot-uekkC560\&t=68s. Acesso em: 15 nov. 2017.

LACERDA, C. B. F. de; SANTOS, L. F. dos; CAETANO, J.F. Estratégias Metodológicas para o Ensino de Alunos Surdos. In: LACERDA, C. B. F. de; SANTOS, L. F (Orgs.) Língua Brasileira de Sinais - Libras: uma introdução. São Carlos: UFSCAR, 2011.

LEBEDEFF, T. B. Práticas bilíngues em Escolas de Surdos: Pennsylvania School for The Deaf e Oak Lodge School. Espaço. Instituto Nacional de Educação de Surdos, Rio de Janeiro, n. 44, p. 67-84, jul./dez. 2015.

LEBEDEFF, T. B. O povo do olho: uma discussão sobre a experiência visual e surdez. In: LEBEDEFF, T. B. (Org.). Letramento visual e surdez. Rio de Janeiro: WAK Editora, 2017, p. 226-251.

LESSA-DE-OLIVEIRA, A. S. C. Libras escrita: o desafio de representar uma língua tridimensional por um sistema de escrita linear. REVEL. v. 10, n. 19, 2012. Disponível em: www.revel.inf.br. Acesso em: 15 jan. 2018. 
OLIVEIRA, T. C. B. C. de. A escrita do aluno surdo: interface entre a Libras e a língua portuguesa. 2009. Tese (Doutorado) - Faculdade de Educação, Universidade Federal da Bahia, 2009.

PELUSO, L.; LODI, A. Claudia B. La experiência visual de los sordos.

Consideraciones políticas, lingüísticas y epistemológicas. Pro-Posições, Campinas, v. 26, n. 3, p. 59-81, dec. 2015. Disponível em:

https://url.gratis/PRuUX. Acesso em: 01 ago. 2020.

QUADROS, R. M. Situando as diferenças implicadas na educação de surdos: inclusão/exclusão. Ponto de Vista, Florianópolis, n.05, p. 81-111, 2003.

SAMPAIO, C. C. R. O uso do Shape Coding no ensino de Língua Portuguesa como segunda língua para Surdos: um estudo sobre variação temporal. 2018. 108f. Dissertação (Mestrado em Letras) - Programa de Pós-Graduação em Letras, Universidade Federal de Pelotas, Pelotas, 2018.

SANTOS, O. C. Uma ideia na mão e uma câmera na cabeça: cinema na educação bilíngue de surdos e surdas. 2020. Tese de doutorado não publicada. São Carlos: UFSCAR, 2020. Disponível em: https://url.gratis/C6y87. Acesso em: 01 ago. 2020.

VIANA, J. M. Adaptação do Shape Coding para o ensino de Língua Portuguesa para surdos do sexto ano do Ensino Fundamental. 2019. Dissertação de Mestrado não publicada. Pelotas: UFPEL, 2019. Disponível em:

http://guaiaca.ufpel.edu.br/handle/prefix/4478. Acesso em: 02 ago. 2020. 